\title{
Interprofessional Competency Frameworks in Health to Inform Curricula Development: Integrative Review
}

\author{
David Loura', Ana Eva Arriscado ${ }^{2}$, Afke Kerkstra ${ }^{3}$, Carla \\ Nascimento ${ }^{2}$, Isa Félix ${ }^{2}$, Mara Pereira Guerreiro ${ }^{4}$, Cristina Baixinho ${ }^{5}$ \\ ${ }^{1}$ Hospital Dona Estefânia, Centro Hospitalar Universitário de Lisboa Central, E.P.E., Lisbon, \\ Portugal; Nursing School of Lisbon, Lisbon, Portugal | davidsloura@gmail.com; \\ https://orcid.org/0000-0002-2700-4365 \\ 2 Nursing School of Lisbon, Lisbon, Portugal | anaevas@campus.esel.pt; https://orcid.org/0000- \\ 0001-9293-4027| carla.nascimento@esel.pt; https://orcid.org/0000-0002-4880-0141| \\ isafelix@esel.pt; https://orcid.org/0000-0001-8186-9506 \\ 3 Inholland University, Haarlem, The Netherlands | afke.kerkstra@inholland.nl; \\ https://orcid.org/0000-0002-8277-3546 \\ ${ }^{4}$ Nursing School of Lisbon; Lisbon, Portugal; Centro de Investigação Interdisciplinar Egas Moniz \\ (CiiEM), Monte de Caparica, Portugal. | mara.guerreiro@esel.pt; \\ https://orcid.org/0000-0001-8192-6080 \\ ${ }^{5}$ Nursing School of Lisbon, Lisbon, Portugal; ciTechCare, Leiria, Portugal | crbaixinho@esel.pt; \\ https://orcid.org/0000-0001-7417-1732
}

\begin{abstract}
The paradigm of collaborative health care delivery drove the development of interprofessional competency frameworks (ICFS). The Train4Health project, funded by the Erasmus + program, aims to improve healthcare students' competencies in behaviour change support to optimize self-care in chronic diseases. As part of this project, we surveyed the landscape of ICFs in health. Our aim was to characterize ICFs in health and its translation into learning outcomes embedded in academic curricula. An integrative review was conducted between March and September 2020 based on a predefined protocol. The search was performed in EBSCO, B-On, Scopus, Web of Science and Joanna Briggs Institute databases. Four articles were eligible, describing ICFs in different domains in health, such as digital healthcare environment, simulation and genetic healthcare. Generally, ICFs were planned and developed by a committee. Students were involved in all four ICFs. These frameworks supported the development of learning outcomes-based curricula, organized in a tiered or straightforward structure, with different learning outcomes depending on their complexity and specialization level. Despite the overlap in some areas across health professions, we found only four ICFs that can guide collaborative education and are linked to learning outcomes. Pursuing this integrated approach, ideally resorting to structured scientific methods, may facilitate competencies attainment and merits further attention.
\end{abstract}

Keywords: Interprofessional Education, health, learning outcomes, competency framework, curricula.

\section{Introduction}

Substantial changes in health care since the late 20th century forced the system to shift into a collaborative environment of practice. Demographic and epidemiological reasons determined these changes, as an increasing range of health professionals provides care to patients, families, or the community, whether in chronic or acute conditions (Little et al., 2012; Olson, \& Brosnan, 2017; Reeves et al., 2013). This demographic change was accompanied by an increase in the complexity of health-disease transitions, challenging the way healthcare is provided and stating that uni-professional interventions were not enough to solve these problems. Effective healthcare delivery is a collaborative task, as it demands health professionals to work with each other productively, using the knowledge obtained through their education and adapting it to each context.

The insurgence of multi-professional health care teams put Interprofessional Education (IPE) on the agenda, and the need of its adoption by higher education institutions, to achieve effective interprofessional work and the delivery of safe and efficient health care 
(Kent et al., 2018). IPE represents a 'departure' from traditional health professions education (Olson \& Brosnon, 2017), where each profession is responsible for the education of their own students and, later on, for the development of professional competencies or standards (Carrol et al., 2014; Illingworth, \& Chelvanayagam, 2017; Kent et al., 2018).

IPE has been addressed by professional organizations and authors. For the World Health Organization (WHO), "IPE occurs when students from two or more professions learn about from and with each other to enable effective collaboration and improve health outcomes" (WHO, 2010, p. 7); WHO's perspective is also supported by the Centre for the Advancement of Interprofessional Education (Illingworth, \& Chelvanayagam, 2017).

Authors like Freeth, Hammick, Reeves, Koppel, and Barr (2005) define IPE as the practice of students from different health professions learning 'from, with and about each other' in preparation for interprofessional work as a health care practitioner (Freeth et al., 2005; Olson \& Brosnon, 2017). Other authors regard IPE from a sociological perspective, in which the relationship between knowledge, identity and professional power can be explored (Olson \& Brosnon, 2017). Despite minor differences, there is a common notion among all authors and organizations - IPE aims to increase understanding and respect about different professional roles, as well as to improve collaboration and patient outcomes.

Despite policy advances, it is recognized that students are still educated in silos, which makes them reluctant to overcome challenges when working with other health care professionals, causing patient safety concerns and dissatisfaction towards interprofessional cooperation (Stadick, 2020; Verapen \& Purkis, 2019). IPE intends to break professional barriers and create cohesion in the multidisciplinary team, in a personcentered paradigm. Competency frameworks (CF) are regarded as a set of statements reflecting what graduates should be able to do in the health service, and not simply in their training. These frameworks can serve as a guide to inform learning outcomes and curricula development and have been advocated in IPE as a form of improving interprofessional collaboration and patient care (WHO, 2010).

Defining the appropriate competencies and learning outcomes (LO) to each professional and educational context, allowing an alignment between their development and implementation (WHO, 2010), is challenging. Competencies are often broad and hardly applicable to the specificity of learning outcomes (Little, et al., 2012; Olson, \& Brosnan, 2017), which formulate and address how competencies should be acquired. Therefore, even though learning outcomes are often less understood than underlying components, they effectively measure competencies achievement, assessing the results of the educational process. To create a solid competency framework, it is required reflection on how competencies and learning outcomes can be optimized and engaged (Thistlethwaite \& Moran, 2010).

The Train4Health project, funded by the Erasmus+ program, aims to improve healthcare students' competencies for behaviour change to support self-care in chronic diseases. As part of this project, we surveyed the landscape of interprofessional competency frameworks (ICFs) in health to inform our work on the development of learning outcomesbased curricula from an ICF on behaviour change support. Therefore, this review aims to identify interprofessional competency frameworks in health associated with a learning outcomes-based curricula.

\section{Methodology}

An integrative review was chosen, as it allows the authors to contact with heterogeneous findings from different scientific points of view, to synthesize knowledge and to incorporate its results in practice (Sousa et al., 2017). The review was conducted between March and September 2020, following a six-phase protocol based on Mendes, Silveira and Galvão (2008): (1) identification of the theme and selection of the hypothesis or research question; (2) establishment of eligibility criteria for inclusion and exclusion of studies; (3) definition of the information to be extracted; (4) critical appraisal of the included studies; (5) data analysis and interpretation; and (6) presentation of the review / synthesis of knowledge. 
The researchers observed all ethical principles when performing this secondary study. Accuracy in the methodological procedures was ensured to guarantee the quality and validity of the study. Data extraction and analysis from the bibliographic sample was developed with profound respect for the authors and its research.

This review was guided by the following research question, elaborated using the acronym PICo (population; intervention and context): "What are the competency frameworks that support learning outcomes-based curricula for interprofessional education in health?" This methodological orientation made it possible to define the eligibility criteria for studies, facilitating the comparison of works, interpretation of data and increasing the accuracy of results. The eligibility criteria were defined as follows:

Table 1. Study eligibility criteria. Lisbon; Portugal. 2020

\begin{tabular}{|c|c|c|}
\hline & Inclusion Criteria & Exclusion Criteria \\
\hline Studies & $\begin{array}{l}\text { Primary studies (quantitative or } \\
\text { qualitative or mixed) with clear } \\
\text { definition of objectives and } \\
\text { methods, published between } \\
2010 \text { and } 2020, \text { written in } \\
\text { Portuguese, Spanish or English }\end{array}$ & $\begin{array}{l}\text { Reviews, opinion articles, } \\
\text { editorials }\end{array}$ \\
\hline Participants & $\begin{array}{c}\text { Participants from two or more } \\
\text { health-related different } \\
\text { professions }\end{array}$ & $\begin{array}{l}\text { Participants from an only health- } \\
\text { related profession }\end{array}$ \\
\hline Interest phenomena & $\begin{array}{l}\text { Development of a learning } \\
\text { outcomes-based curricula } \\
\text { through the definition of an } \\
\text { interprofessional competency } \\
\text { framework }\end{array}$ & $\begin{array}{l}\text { Interprofessional competency } \\
\text { frameworks without association } \\
\text { to curricula development }\end{array}$ \\
\hline Context & $\begin{array}{l}\text { Interprofessional education in } \\
\text { health }\end{array}$ & Non-health-related education \\
\hline
\end{tabular}

The descriptors used were: Competency Framework, Curriculum, Interprofessional Education, and Health and these descriptors were also used in Portuguese and Spanish and in associations (AND and OR). The research was carried out in the databases available on EBSCO, B-On, SCOPUS, ISI and JBI platforms. The search was restricted to the years 2010 to 2020. To optimize the article selection, the process was developed by three researchers, who summarized it into a flowchart, as it is presented:

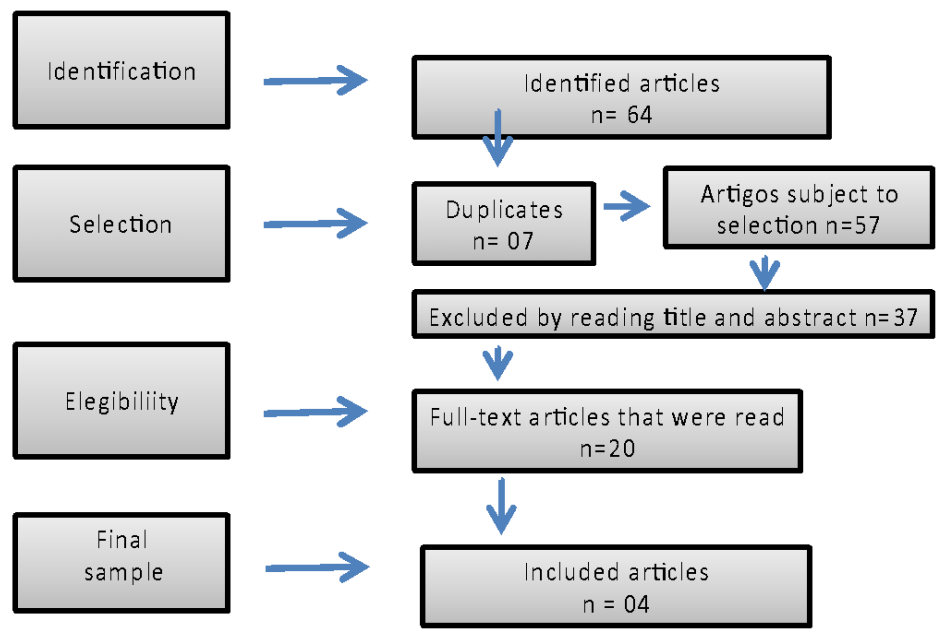

Fig. 1. Flowchart for selecting articles from the bibliographic sample. Lisbon; Portugal. 2020. 
The potential sample comprised 64 studies. Seven (07) articles were duplicated. Thirtyseven (37) articles were rejected by title and abstract. The reading and analysis of the study summary conditioned the selection to twenty (20) and the analysis of the full text to four (04). The 16 studies read in their entirety that were excluded had competency frameworks: two referred to teacher competencies, one to medical competencies and one to nurses competencies. The remaining 12, despite presenting interprofessional CFs, had no associated curricula. After the identification of the final sample, the authors developed a table to optimize data collection, which included the main findings of each study and its contribution to our review, in alignment with our aim. This table is presented in its short version in the next chapter.

\section{Results}

Over a 10-year length period of search (2010-2020), we identified only four interprofessional CFs that support the development of curricula in the specific area of the competencies, which they report (table 2). One was published in 2010 (Skirton et al., 2010), one in 2013 (Greidanus et al., 2013), one in 2017 (Karugutia et al., 2017) and another in 2019 (Pontefract \& Wilson, 2019) (Table 1). Two took place in the UK (Skirton et al., 2010; Pontefract \& Wilson, 2019), one in Canada (Greidanus et al., 2013) and another in South Africa (Karugutia et al., 2017).

Table 2. Articles included in the Integrative Review. Lisbon; Portugal. 2020.

\begin{tabular}{|c|c|c|c|}
\hline $\begin{array}{c}\text { Authors (year) } \\
\text { Country }\end{array}$ & Professionals & Aims & Results \\
\hline $\begin{array}{l}\text { Skirton, Lewis, Kent, } \\
\text { Coviello, and } \\
\text { Members of } \\
\text { Eurogentest Unit } 6 \\
\text { and ESHG Education } \\
\text { Committee } \\
\text { (2010) } \\
\text { UK }\end{array}$ & $\begin{array}{l}\text { Medical doctors / } \\
\text { Physicians, Nurses } \\
\text { and Midwives, } \\
\text { Dentists Laboratory } \\
\text { professionals, divided } \\
\text { into three clinical } \\
\text { fields of practice: } \\
\text { Generalists } \\
\text { professionals; } \\
\text { Specialized health } \\
\text { professionals; } \\
\text { Specialists in } \\
\text { Genetics. }\end{array}$ & $\begin{array}{l}\text { To produce a set of } \\
\text { competencies that } \\
\text { could be applied } \\
\text { across Europe to the } \\
\text { range of health } \\
\text { professionals involved } \\
\text { in provision of genetic } \\
\text { health care. }\end{array}$ & $\begin{array}{l}\text { Competency } \\
\text { framework } \\
\text { development by a } \\
\text { working group } \\
\text { LO uniprofessional } \\
\text { and interprofessional - } \\
\text { cognitive + affective + } \\
\text { psychomotor } \\
\text { Connection with } \\
\text { professional } \\
\text { competencies. } \\
\text { Competencies and } \\
\text { LO organized into } \\
\text { tiers of specialization. }\end{array}$ \\
\hline $\begin{array}{l}\text { Greidanus, King, } \\
\text { LoVerso and Ansell } \\
\text { (2013) } \\
\text { Canada }\end{array}$ & $\begin{array}{l}\text { Practical nursing (2- } \\
\text { year diploma program } \\
\text { at a community } \\
\text { college). } \\
\text { Bachelor of nursing } \\
\text { (4-year degree). } \\
\text { Medicine Respiratory } \\
\text { therapy }\end{array}$ & $\begin{array}{l}\text { To suggest one } \\
\text { process for revising } \\
\text { learning objectives } \\
\text { based on review of } \\
\text { the simulation, the } \\
\text { debriefing, and the } \\
\text { student feedback on } \\
\text { reported learning. } \\
\text { Implications for } \\
\text { curriculum integration } \\
\text { are discussed. }\end{array}$ & $\begin{array}{l}\text { LO associated to the } \\
\text { Canadian } \\
\text { Interprofessional } \\
\text { Health Collaborative } \\
\text { Competencies. } \\
\text { LO } \\
\text { interprofessional/gene } \\
\text { ric - cognitive + } \\
\text { affective + } \\
\text { psychomotor } \\
\text { Student involvement } \\
\text { conceiving the } \\
\text { competency } \\
\text { framework }\end{array}$ \\
\hline
\end{tabular}




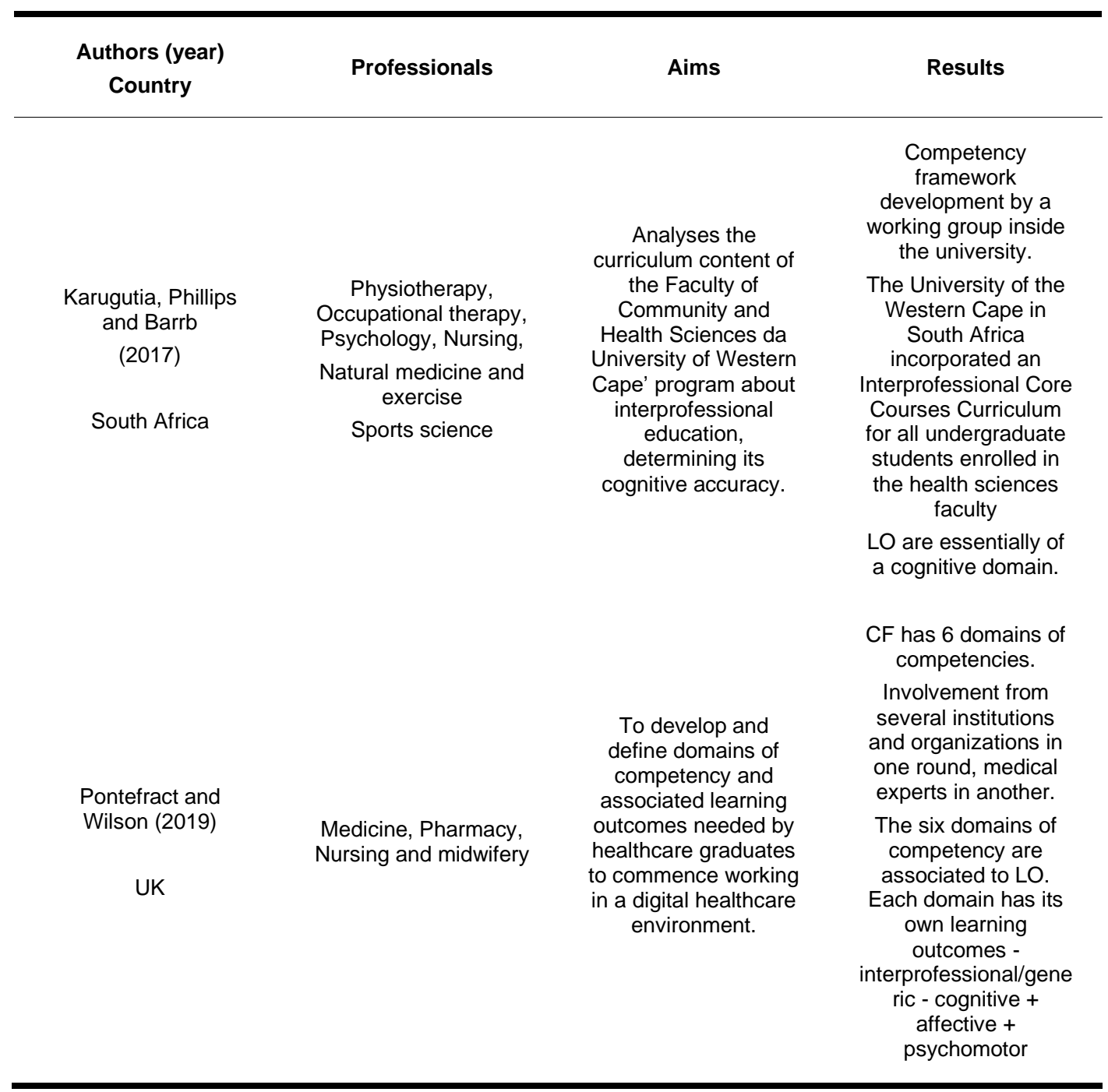

It is clear from the articles' own objectives that they were constructed in different paradigms: from the development of CF and the curricula (Karugutia et al., 2017; Pontefract \& Wilson, 2019; Skirton et al., 2010) to the evaluation of the curricula itself (Greidanus et al., 2013). In the study of Greidanus et al. (2013) the CF is not presented because the objective was to evaluate revising learning objectives based on review of the simulation, the debriefing, and the student feedback on reported learning to discuss the curriculum that is aligned with the Canadian Interprofessional Health Collaborative Competencies.

\section{Discussion}

The articles included in this integrative review describe interprofessional CFs in different domains in health. Although most of the studies show a major focus on their scientific theme, we considered that the details of the CF contributes to our work and answers the research question initially defined. However, the number of studies that resulted from this review appear to be substantially few gives the amplitude of the topic in analysis. This fact opens the door to the lack of literature concerning this matter, recognizing the importance of effective implementation of the interprofessional paradigm in health.

Through the present review, we discovered that IPE and collaboration is a concern to universities and stakeholders. Indeed, the WHO (2010) has been making recommendations since 2010, referring that IPE is key to guarantee that health students of today work as collaborative health professionals tomorrow, moving health systems from 
fragmentation to a strengthened position through sharing case management and providing better services to the community. This positive interaction is identified in the literature as interprofessional collaborative practice, where multiple health care workers, each one with different professional backgrounds, work together with patients to deliver the finest quality of care (Interprofessional Education Collaborative Expert Panel, 2011; Stadick, 2020). Several systematic reviews corroborate this perspective, describing positive outcomes in collaboration, team behaviour, mortality rates, error rates, patient length of stay, among others (Kent et al., 2018; Reeves et al., 2013; Reeves et al., 2016). Another important recommendation is the involvement of students in research (Loura et al., 2020).

As to promote the development of collaborative teams of health professionals, the "how", "when" and "where" of IPE are issues that need to be addressed (Kent et al., 2018). Thinking about how to operationalize IPE, the first word that arises from the evidence is 'challenge', also named as 'barriers'. Fundamentally, there are a number of reasons that expose the difficulty of getting IPE to the field: geographical (e.g. distance between schools or universities), cultural (e.g. organizational culture that affects the way professionals relate to each other), logistic (e.g. the need for larger classrooms and difficulties with scheduling) and evaluation (e.g. accuracy, assessment of team skills and impact on practice and patient outcomes) issues have to be overcome to make IPE possible (Carroll et al., 2014; Guraya \& Barr, 2018; Illingworth \& Chelvanayagam, 2017; Lapkin et al., 2013; Mitchell et al., 2020; Neocleous, 2014; Thistlethwaite, 2015).

Considering these conditions and difficulties, competency frameworks aligned with learning outcomes-based curricula might be an answer to ensure proper appropriation of knowledge and implementation of IPE in practice. The competency-based education (CBE) provides a useful alternative to time-based models for preparing health professionals and constructing educational programs because it implies a curriculum framework, in which learners and educators are more accountable, the program is flexible and adapts to learner progress, and learners take responsibility for their own learning and development (Weller, Naik, \& Ryan, 2020). This perspective is aligned with our findings, in particular with the study of Greidanus et al. (2013), where students were involved at an early stage, conceiving the competency framework itself inside a larger group.

Hawkins et al. (2015) advocate that this approach has advantages that includes: a focus on the outcomes and in what the learner need to achieve; requirements for multifaceted assessment that embraces formative and summative approaches; support of a flexible, time-independent trajectory through the curriculum; and improves the information and articulation to stakeholders with a shared set of expectations and a common language for education, assessment and regulation. All the studies included in our sample present CFs embedded in this ideology, describing the use of documents defining professional competencies as a basis for its creation (Skirton et al., 2010; Greidanus et al., 2013), as well as the importance of working groups to raise consensus on CFs content (in some cases, with the contribution of stakeholders and experts). Also, the structure of these CF and associated curriculas were different depending on the theme's size and latitude: Skirton et al. (2010) described the tiered composition of a curricula, as opposed to a more straightforward infrastructure adopted by the other authors.

Teaching sitting on an IPE program is complex and requires flexibility and understanding of the diverse backgrounds within the combination of professional groups present (Olson \& Brosnan, 2017). This issue raises questions about the origin of the learning outcomes, which can be strictly multi-professional or different for each of the professional groups, even if the theme is interprofessional. Our review was able to identify one study in which learning outcomes were two-sided: a specific curriculum based on each profession or area was added to the generic one (Skirton et al., 2010). In the other studies, learning outcomes were generic and independent.

Furthermore, the agreement on the methods the institutions will use to help students develop key interprofessional competencies for collaborative practice has to be reached (Banister et al., 2020). Teaching and learning approaches vary from multi-professional dynamics, where students from different professions learn along with each other, to short activities where students have the opportunity to work together on a more specific subject, 
and even to training wards, with effective cooperation caring for a real patient in a clinical context (Oandasan \& Reeves, 2005; Olson \& Brosnan, 2017; Olson \& Bialocerkowski, 2014). These distinct methodologies raise issues about how to conceive and adapt learning outcomes to the activities that are actually taken, going from a more cognitive approach to a substantial affective or psychomotor dynamic, considering Bloom's Taxonomy (Cedefop, 2017). In our findings, learning outcomes associated with CFs were mostly multiple (cognitive, psychomotor and affective), excluding the work of Karugutia et al. (2017), in which learning outcomes were only cognitive. However, all studies presented a cognitive domain majority in learning outcomes.

Besides the relevance of our findings, it is our obligation to point out that a major limitation of our study is the dimension of the sample and the low-range of the structural issues described. The existence of a better detailed study design would be important to understand deeper how to conceive interprofessional CF and align them with learning outcomes in a complex health and education system.

\section{Final Considerations}

Interprofessional education has been appointed as an effective solution to promote collaboration between healthcare professionals, develop and enhance clinical practice and foster relevant outcomes for people. However, and despite the overlap in some areas across health professions, we found only four interprofessional CFs that can guide collaborative education and are linked to learning outcomes.

Competency frameworks can be useful guiding the definition and development of learning outcomes-based curricula, supporting students' involvement and accountability on their learning, knowledge acquisition and competency development. Although our sample includes only four articles, in which the competency areas are different, we were able to identify that cognitive learning outcomes assume a main position concerning the implementation of IPE in curricula.

IPE needs to be implemented in health and education settings to thrive and show its importance. While educators need to be passionate about IPE to make it effective, students need to feel that it is relevant for their clinical practice. In addition, schools, universities, and clinical institutions need to encourage and support this kind of practice, debating, at least internally, its importance and considering when is the best timing to incorporate IPE in academic curricula. A greater and still unknown future seems to be ahead of the scientific community regarding IPE and its inclusion in CFs linked to learning outcomes. Articulation between clinical and academic contexts, where a model of competencies can be useful in generating a standardized evaluation of specific program objectives, measuring outcomes and providing future direction, is needed, as well as resorted or structured scientific methods that may facilitate competencies attainment.

\section{References}

Banister, G., Portney, L., Vega-Barachowitz, C., Jampel, A., Schnider, M., Inzana, R., .., Knab, M. (2020). The interprofessional dedicated education unit: Design, implementation and evaluation of an innovative model for fostering interprofessional collaborative practice. Journal of Interprofessional Education and Practice. 19(2), 1-10. https://doi.org/10.1016/j.xjep.2019.100308

Carroll, L., Ali, M., Cuff, P., Huffman, M., Kelly, B., Kishore, S., ..., Vedanthan, R. (2014). Envisioning a transdisciplinary university Interprofessional Global Health Education. The Journal of Law, Medicine \& Ethics. 42(2), 17-25. https://doi.org/10.1111/jlme.12183.

Cedefop (2017). Defining, writing and applying learning outcomes: a European handbook. European Centre for the Development of Vocational Training. http://dx.doi.org/10.2801/566770 
Freeth, D., Hammick, M., Reeves, S., Koppel, I., \& Barr, H. (2005). Effective interprofessional education: Development, delivery and evaluation. Blackwell Publishing.

Greidanus, E., King, S., LoVerso, T., \& Ansell, L.D. (2013). Interprofessional learning objectives for health team simulations. Journal of Nursing Education, 52(6), 311-316. https://doi.org/10.3928/01484834-20130509-02.

Guraya, S. \& Barr, H. (2018). The effectiveness of interprofessional education in healthcare: A systematic review and meta-analysis. The Kaohsiung Journal of Medical Sciences, 34(3), 160-165. https://doi.org/10.1016/j.kjms.2017.12.009.

Harden, R. (2015) Interprofessional education: The magical mystery tour now less of a mystery. Anatomical Sciences Education, 8(4), 291-5. https://doi.org/10.1002/ase.1552.

Hawkins R. E., Welcher C. M., Holmboe E. S., Kirk L. M., Norcini J. J., Simons K. B., \& Skochelak S. E. (2015). Implementation of competency-based medical education: are we addressing the concerns and challenges? Medical Education, 49(11), 1086-102. https://doi.org/10.1111/medu.12831

Illingworth, P. \& Chelvanayagam, S. (2017). Benefits of interprofessional education in health care: Ten years on. The British Journal of Nursing, 26(14), 813-818. https://doi.org/10.12968/bjon.2017.26.14.813

Interprofessional Education Collaborative Expert Panel. (2011). Core competencies for interprofessional collaborative practice: Report of an expert panel. Interprofessional Education Collaborative.

Karugutia, W. M., Phillips, J., \& Barr, H. (2017). Analysing the cognitive rigor of interprofessional curriculum using the Depth of Knowledge framework. Journal of Interprofessional Care, 31(4), 529-532. https://doi.org/10.1080/13561820.2017.1310718.

Kent, F., Nankkervis, K., Johnson, C., Hodgkinson, M., Baulch, J. \& Haines, T. (2018). 'More effort and more time.' Considerations in the establishment of interprofessional education programs in the workplace. Journal of Interprofessional Care, 32(1), 89-94. https://doi.org/10.1080/13561820.2017.1381076.

Lapkin S., Levett-Jones, T. \& Gilligan, C. (2013). A systematic review of the effectiveness of interprofessional education in health professional programs. Nurse Education Today, 33(2), 90-102. https://doi.org/10.1016/j.nedt.2011.11.006

Lawliss, T., Wicks, A., Jamieson, M., Haughey, A. \& Grealish, L. (2016). Interprofessional education in practice: Evaluation of a work integrated aged care program. Nurse Education in Practice, 17(2), 161-166. https://doi.org/10.1016/j.nepr.2015.11.010

Little, M., Lipworth, W., Gordon, J., Markham, P. \& Kerridge, I. (2012). Values-based medicine and modest foundationalism. Journal of Evaluation in Clinical Practice, 18(5), 1020-1026. https://doi,org/10.1111/j.1365-2753.2012.01911.x.

Loura, D., Bernardes, R., Baixinho, C.L., Rafael, H., Félix, I., \& Guerreiro, M. (2020). Aprender em projetos de investigação durante a licenciatura em enfermagem: revisão integrativa da literatura [Learning in research projects during nursing undergraduate degree: integrative literature review]. New Trends in Qualitative Research, 3(2020), 293-304. https://doi.org/10.36367/ntqr.3.2020.293-304

Mendes, K.D.S., Silveira, R.C.C.P., \& Galvão, C.M. (2008). Revisão integrativa: método de pesquisa para a incorporação de evidências na saúde e na enfermagem [Integrative review: search method for evidence incorporation in health and nursing]. Texto \& Contexto Enfermagem, 17(4), 758-764. http://dx.doi.org/10.1590/S0104-07072008000400018

Mitchell, A., Ankam, N., Umland, E., Earland, T., Dallas, S. \& Ukanna, A. (2020). New Directions for Teaching and Learning, 2020(162), 145-155. https://doi.org/10.1002/tl.20399

Murray-Davies B., Marshall, M. \& Gordon, F. (2012). From school to work: Promoting the application of pre-qualification interprofessional education in the clinical workplace. Nurse Education in Practice, 12(5), 289-96. https://doi.org/10.1016/j.nepr.2011.10.009.

Neocleous, A. (2014). Interprofessional learning. How can it enhance education? Whitireia Journal of Nursing, Health and Social Services, 21(2014), 23-28. https://www.thefreelibrary.com/Interprofessional+education\%3A+how+can+it+enhance+learni ng\%3F-a0408158291. 
Oandasan, I. \& Reeves, S. (2005). Key elements of interprofessional education. Part 1: The learner, the educator and the learning context. Journal of Interprofessional Care, 19(1), 21 38. https://doi.org/10.1080/13561820500083550.

Olson, R. \& Bialocerkowski, A. (2014). Interprofessional education in allied health: A systematic review. Medical Education, 48(3), 236-246. https://doi.org/10.1111/medu.12290.

Olson, R. \& Brosnan, C. (2017). Examining interprofessional education through the lens of interdisciplinarity: Power, knowledge and new ontological subjects. Minerva, 55(3), 299-319. https://doi.org/10.1007/s11024-017-9316-2

Pontefract, S.K., \& Wilson, K. (2019). Using electronic patient records: Defining learning outcomes for undergraduate education. BMC Medical Education. 19(30), 1-8. https://doi.org/10.1186/s12909-019-1466-5

Reeves, S., Perrier, L., Goldman, J., Freeth, D. \& Zwarenstein, M. (2013). Interprofessional education: Effects on professional practice and healthcare outcomes (update). Cochrane Database of Systematic Reviews, 2013(3), CD002213. https://doi.org/10.1002/14651858.CD002213.pub3

Reeves, S., Fletcher, S., Barr, H., Birch, I., Boet, S., Davies, N., . . Kitto, S. (2016). A BEME systematic review of the effects of interprofessional education: BEME Guide No. 39. Medical Teacher, 38(7), 656-668. https://doi.org/10.3109/0142159X.2016.1173663.

Skirton, H., Lewis, C., Kent, A., Coviello, D. A., \& Members of Eurogentest Unit 6 and ESHG Education Committee (2010). Genetic education and the challenge of genomic medicine: Development of core competences to support preparation of health professionals in Europe.

European Journal of Human Genetics, 18(9), 972-977. https://doi.org/10.1038/ejhg.2010.64

Sousa, L. M. M., Firmino, C. F., Marques-Vieira, C. M. A., Severino, S. S. P. S., \& Pestana, H. C. F. C. (2018). Revisões da literatura científica: tipos, métodos e aplicações em enfermagem [Scientific literature reviews: types, methods and applications in nursing]. Revista Portuguesa de Enfermagem de Reabilitação, 1(1), 45-54. https://core.ac.uk/download/pdf/232112845.pdf.

Stadick, J. (2020). The relationship between interprofessional education and health care professional's attitudes towards teamwork and interprofessional collaborative competencies. Journal of Interprofessional Education \& Practice, 19(2020), 1-7. https://doi.org/10.1016/j.xjep.2020.100346

Thistlethwaite, J., \& Moran, M. (2010). Learning outcomes for interprofessional education (IPE): Literature review and synthesis. Journal of Interprofessional Care, 24(5), 503-513. https://doi.org/10.3109/13561820.2010.483366

Thistlethwaite, J. E., Forman, D., Matthews, L. R., Rogers, G. D., Steketee, C., \& Yassine, T. (2014). Competencies and frameworks in interprofessional education: a comparative analysis. Academic Medicine, 89(6), 869-875. https://doi.org/10.1097/ACM.0000000000000249.

Thistlethwaite, J. (2015). Interprofessional education: implications and development for medical education. Educación Médica, 16(1),68-73. https://doi.org/10.1016/j.edumed.2015.04.007

Veerapen, K., \& Purkis, M. (2014). Implications of early workplace experiences on continuing interprofessional education for physicians and nurses. Journal of Interprofessional Care, 28(3), 218-225. https://doi.org/10.3109/13561820.2014.884552.

Weller J. M., Naik V. N., \& Ryan J. (2020). Systematic review and narrative synthesis of competency-based medical education in anesthesia. British Journal of Anesthesia, 124(6), 748-760. https://doi.org/10.1016/j.bja.2019.10.025

World Health Organization (2010). Framework for Action on Interprofessional Education \& Collaborative Practice. WHO. 